\title{
Víctimas en justicia restaurativa: isujetos activos o en necesidad? Un estudio europeo desde la perspectiva de operadores sociales*
}

Victims in Restorative Justice: Active Persons or Individuals in Need? A European Study from Practitioners' point of view

Recibido: 1 de marzo de 2015 | Revisado: 1 junio de 2015 | Aceptado: 1 agosto de 2015

\author{
DANIELA BOLÍVAR ** \\ INGE VANFRAECHEM ***
}

doi:10.11144/Javeriana.up14-4.vjrs

Para citar este artículo: Bolívar, D., \& Vanfraechem, I. (2015). Víctimas en justicia restaurativa: isujetos activos o en necesidad? Un estudio europeo desde la perspectiva de operadores sociales. Universitas Psychologica, 14(4), 1437-1458. http://dx.doi. org/10.11144/Javeriana.up14-4.vjrs

Esta investigación fue financiada por Criminal Justice Programme European Commission Directorate-General Justice, Freedom and Security, JUST/2009/JPEN/AG/0628.

*** Profesor asistente. Departamento de Psicología, Universidad de Chile.dbolivar@u.uchile.cl

**** Investigadora. Instituto de Criminología de Lovaina (LINC). Universidad de Lovaina (K.U. Leuven)

\section{RESUMEN}

A la indiscutible proliferación del uso de la justicia restaurativa en Europa se ha sumado evidencia que sugiere que su práctica está quedando en deuda con las víctimas de delito. Las políticas de justicia restaurativa parecen no estar constituyendo espacios genuinos de participación: las víctimas no tienen acceso a la información sobre estos servicios y su implementación aún está lejos de considerar plenamente sus necesidades. El objetivo de este estudio fue explorar las creencias que tienen los propios profesionales de justicia restaurativa y de programas de apoyo a la víctima sobre victimización y justicia restaurativa, y discutir el papel potencial de estas creencias en el desarrollo de estos obstaculizadores de participación. Este estudio, de carácter descriptivo y exploratorio, utilizó metodología cualitativa y cuantitativa, e involucró una muestra de 125 profesionales de justicia restaurativa y programas de apoyo a la víctima, correspondientes a 19 países europeos. Los resultados sugieren que, si bien los profesionales reconocen los beneficios que la justicia restaurativa puede ofrecer a víctimas de delitos, existen también concepciones que parecen prevenir a los profesionales de dar mayor espacio a las víctimas en la toma de decisiones.

Palabras clave

participación; creencias; justicia restaurativa; víctimas de delito; políticas

\section{A B S T R ACT}

Restorative justice has proliferated in europe and there is evidence suggesting that their practice is falling in debt to the victims of crime. The restorative justice policies seems not to be constituing genuine spaces of participating. Restorative justice policies appear not to be forming genuine opportunities for participation: victims do not have access to information about these services and their implementation is still far from fully consider their needs. This study was two objectives: explore beliefs about the victimization and restorative justice of professionals from restorative justice and victim support programs, and discuss the potential role of these beliefs on barriers to participation. This is a descriptive and exploratory study that used a qualitative and quantitative methodology, and considered a sample of 125 professionals from restorative justice and victim support programs, from 19 different European countries. The results suggest that professionals recognize the benefits that restorative justice can offer to victims of crime, however there are conceptions that appear to limit professionals to give more space to victims in taking decisions.

Keywords

participation; beliefs; restorative justice; victims of crime; policies 
En las últimas décadas, Europa ha sido testigo de cambios centrales en la manera de concebir y entender la reacción social ante conflictos o delitos criminales. Si bien los procedimientos judiciales tradicionales siguen liderando la respuesta social, estrategias alternativas que abogan por una reacción participativa e inclusiva han ido ganando terreno. Un ejemplo de ello es el evidente aumento de programas de justicia restaurativa (JR) en los últimos treinta años. Estrategias como la mediación víctima-ofensor, las conferencias familiares y los círculos de paz se cuentan cada vez más frecuentemente entre las estrategias implementadas para dar respuesta a los conflictos penales, tanto en Europa como en otros lugares del globo, incluida Latinoamérica (ver por ejemplo, Ehret, Dhondt, Fellegi, \& Szegö, 2013; Zinsstag \& Vanfraechem, 2012).

\section{Definiendo justicia restaurativa}

Las Naciones Unidas define JR como "una forma de responder al comportamiento delictivo balanceando las necesidades de la comunidad, las víctimas y los delincuentes" (Organización de las Naciones Unidas, 2006, p. 6). Para esta Organización, la JR es una metodología que permite solucionar problemas a través del involucramiento de los principales afectados y del ofrecimiento de ayuda desde la comunidad, tanto para la víctima como para el ofensor. Esta metodología enfatizaría la reconstrucción de las relaciones humanas y la búsqueda de acuerdos, y tendría la capacidad de adaptarse a contextos culturales y sociales distintos.

La JR comenzó a desarrollarse desde la necesidad de dar respuesta a tres problemas:

A. El abandono que experimenta la víctima por parte del proceso penal al ser reducida a un rol testifical, y el daño que dicho proceso puede ocasionarle al no respetar sus tiempos ni responder a sus necesidades (Dignan, 2005).

B. El cuestionamiento al sistema penal y sus instrumentos de control (como la prisión) en términos de su rol preventivo y resocializador del ofensor (Braithwaite, 2002).

C. La limitación del sistema penal tradicional para dar respuestas a distintas realidades sociales y culturales, involucrando a los miembros de la comunidad (McCold, 2004; Pranis, 2001).

Existen muchas prácticas y definiciones de JR. Sin embargo, independientemente a las características de proceso restaurativo, pueden identificarse tres supuestos centrales. Primero, la JR asume que no solo la víctima es afectada por la ofensa. El ofensor y la comunidad también son afectados por el delito. Por lo tanto, la JR es concebida como un modelo triangular donde víctima-ofensor-comunidad son sus principales protagonistas ("stakeholders") (McCold \& Wachtel, 2002). En concreto, esto significa que toda práctica restaurativa debe involucrar a estos tres actores con el fin de dar una respuesta comprehensiva al delito. Segundo, la JR asume que los individuos tienen la capacidad y los recursos para enfrentar y resolver por sí mismos el conflicto que los afecta. La JR (jueces y abogados), al tomar el conflicto de quienes lo "robaron" y devolverlo a sus "dueños", promueve el empoderamiento individual y comunitario (Christie, 1977). Tercero, el enfoque restaurativo asume que el delito no es una ofensa contra el Estado, como los modelos retributivos asumen, sino principalmente daño ejercido contra personas y contra relaciones humanas. En otras palabras, la JR concibe el "daño" producido por el delito como un fenómeno que tiene un componente individual (la víctima y el ofensor) y social (la relación del ofensor con la comunidad y la relación ente ofensor y víctima) (Walgrave, 2008).

La mayoría de los autores coinciden, por lo tanto, en que la JR tiene dos objetivos centrales: a) la reparación del daño producido por la ofensa (Aertsen, Mackay, Pelikan, Willemsens, \& Wright, 2004; Daly, 2000; Zehr, 2002) y b) el "empoderamiento" de aquellos afectados por la ofensa (Barton, 2000; Strang, 2004). 
VÍCTIMAS EN JUSTICIA RESTAURATIVA: ¿SUJETOS ACTIVOS O EN NECESIDAD? UN ESTUDIO EUROPEO DESDE LA PERSPECTIVA DE OPERADORES SOCIALES

\section{Participación en justicia restaurativa: buscando inclusión y empoderamiento en víctimas de delito ${ }^{1}$}

Las Naciones Unidas define como "proceso restaurativo" cualquier proceso en que las partes afectadas (ofensor, víctima y miembros de la comunidad) "participan en conjunto y activamente en la resolución de los asuntos derivados del delito, generalmente con la ayuda de un facilitador" (Organización de las Naciones Unidas, 2006, p. 7). En concreto, es una práctica estrictamente voluntaria que permite a la víctima entablar un diálogo (directo o indirecto) con el ofensor y confrontarlo con el impacto del delito, expresar emociones, hacer preguntas para entender la experiencia vivida (“ipor qué yo?"), escuchar las explicaciones de la otra parte y "ver" sus expresiones de remordimiento (Aertsen \& Peters, 1998; Latimer et al., 2005; Morris, Maxwell, \& Robertson,1993; Rugge \& Cormier, 2003; Shapland et al., 2007; Sherman \& Strang, 2007; Umbreit, 1994; Umbreit, Coates, \& Vos, 2004; Wemmers \& Canuto, 2002). El proceso también permite a la víctima formar parte de la toma de decisiones, ya que las partes involucradas en el proceso (víctima, ofensor y, en ocasiones, comunidad) discuten maneras en las que el daño puede ser reparado. Dichas decisiones o acuerdos pueden ir desde aceptar un ofrecimiento de disculpas hasta acordar una compensación económica, pasando por compromisos del ofensor para participar en tratamientos de rehabilitación, programas de reinserción educacional, etc. (Shapland et al., 2011).

Cuando la justicia restaurativa constituye un espacio genuino de participación, esta debería ser una fuente de empoderamiento (Larson \& Zehr, 2007; Zehr, 2005) y de "justicia procedimental" (De Mesmaecker, 2011; Van Camp \& Wemmers, 2013), ayudando al proceso emocional de la víctima,

1 La justicia restaurativa debe constituir una experiencia "win-win" para todos sus actores, incluidos ofensores y la comunidad (Koss, 2014; Latimer, Dowden, \& Muise, 2005; Miller, 2011; Miller \& Hefner, 2015; Pranis, 2001; Roberts, 1995; Shapland, Robinson, \& Sorsby, 2011; Strang, 2012; Sherman \& Strang, 2007; Sherman, Strang, Mayo-Wilson, Woods, \& Ariel, 2014; Umbreit, Vos, Coates, \& Brown, 2003). fomentando un sentimiento de "cierre" y reduciendo síntomas como miedo, angustia y estrés postraumático (Angel, 2005; Beven, Hall, Froyland, Steels, \& Goulding, 2005; Bolívar, en imprenta; Flaten, 1996; Gustafson, 2005; Roberts, 1995; Shapland et al., 2011; Strang, 2002; Van Camp \& Wemmers, 2013; Zebel, 2012).

\section{Prácticas de justicia restaurativa en Europa: ioportunidades genuinas de participación?}

Las principales instancias que han promovido y regulado el uso de la JR en el Continente han sido el Consejo de Europa y la Unión Europa. El Consejo de Europa estableció en 1985 las Recomendaciones en relación con la posición de la víctima en procesos criminales (Recommendation No. R (85) 11) e invitó a los Estados miembros a considerar una mayor participación de las partes en la resolución del caso penal, como lo es la mediación víctima-ofensor y las conferencias familiares. En 1999, el Consejo de Europa presentó sus Recomendaciones para mediación en materias penales (Recommendation No. R (99) 19), donde se establecen las principales pautas para su implementación: estricta voluntariedad para participar en el proceso y aceptar sus acuerdos, confidencialidad de sus contenidos (también para las autoridades judiciales), acceso para todos los ciudadanos, disponibilidad de la JR en todos los momentos del circuito penal e independencia de los programas de mediación respecto del sistema penal.

Las Recomendaciones del Consejo de Europa son, como su nombre lo indica, recomendaciones, y por lo tanto su implementación no es una obligación para los países europeos, sino una pauta para definir políticas a nivel local. Distinto es el caso de las regulaciones promulgadas por la Unión Europea, las cuales tienen carácter obligatorio. En relación con la JR, se han promulgado dos normativas pertinentes: en 2001, la Decisión Marco de la Posición de la Víctima en Procedimientos Criminales (2001/220/JHA) y en 2012 la Directiva sobre Estándares Mínimos de Derechos de las Víctimas (Directiva 2012/29/EU), que reemplaza la Decisión Marco. Ambas regulaciones se refieren a 
la situación de las víctimas de delitos y si bien no se focalizan exclusivamente en los programas de JR, estos son tomados en cuenta.

La Directiva 2012/29/EU plantea la obligatoriedad de informar a las víctimas de delitos sobre la disponibilidad de servicios de JR. Sin embargo, la Directiva, a diferencia de las Recomendaciones, acentúa las medidas de protección que los programas de JR deben adoptar para proteger a víctimas vulnerables (Lauwaert, 2015), resaltando nociones como evaluaciones de riesgo, víctimas vulnerables y medidas de protección.

A nivel local, el rol que los procesos de justicia restaurativa tiene o puede tener dentro del procedimiento penal dependerá del marco legislativo de cada país. Si bien la JR ha sido utilizada en casos graves y como un servicio complementario al procedimiento penal, como es el caso de Bélgica, Holanda, Canadá, Estados Unidos y Nueva Zelanda (Aertsen et al., 2004), estudios han indicado que en su gran mayoría (como también sucede en Europa), la JR ha sido usada como un sistema alternativo de resolución de conflictos que puede reemplazar al proceso judicial o tener un impacto en la definición de la pena, como es el caso de España, Portugal, Finlandia y Austria (Bolívar, 2014; Bolívar, Pelikan, $\&$ Lemmone, 2015). En otras palabras, la JR ha tendido a ser concebida más frecuentemente como una medida judicial, y con menos frecuencia como un servicio para la ciudadanía (Aertsen, 2006).

\section{¿Víctimas y participantes?}

Evidencia reciente ha sugerido que en la práctica europea de justicia restaurativa existen dos tipos de barreras, por parte de las víctimas, para una participación genuina en estos procesos. En primer lugar, las víctimas tienden a no informarse sobre esta posibilidad, lo que limita de manera importante su acceso a esta práctica. Informes europeos, tales como los elaborados por APAV e INTERVICT (2009) y Matrix y Felix (2010), confirman la falta de información como uno de los problemas más importantes que afecta a las víctimas de delitos en el contexto de la JR. Otras investigaciones, como las de Tamarit, Villacampa y Filella (2010) y Maxlina- rayan (2014), han llegado a similares conclusiones. En segundo lugar, la práctica de JR parece no estar considerando de manera suficiente las necesidades de las víctimas. En un estudio reciente, se ha concluido que la implementación europea de JR se ha constituido principalmente en un mecanismo de "diversificación" (diversion), lo que significa que se ha focalizado en delitos menores, procesos más rápidos y principalmente centrados en el resultado, poniendo en riesgo la centralidad de la víctima en el proceso. Estos elementos de contexto estarían, además, pre-determinando el tipo de temáticas que se discuten en estas instancias, limitando así el potencial de comunicación entre las partes (Vanfraechem, Bolívar, \& Aertsen, 2015).

La presente investigación se ha desarrollado bajo la hipótesis de que los problemas previamente mencionados se originan, en parte, en las creencias que tienen profesionales u operadores sociales sobre la victimización criminal. Algunas de estas creencias serían la base de vacilaciones sobre las capacidades y recursos que podrían tener las víctimas de delitos para involucrarse en un proceso de JR. Esta hipótesis se fundamenta en las contradicciones que habitualmente se encuentran en el discurso de la JR: por un lado se promueve participación a todas las víctimas y en todas las circunstancias, lo que presupone confianza en los recursos personales de los ciudadanos afectados por delitos (como lo hace la Recomendación del Consejo de Europa R (99) 19), cuando, por otro, se enfatizan las vulnerabilidades y por tanto los riesgos de la participación de víctimas en la JR (como lo hace la Directiva 2012/29/EU de la Unión Europea). En la academia también coexisten visiones focalizadas en necesidades con visiones centradas en los recursos (Aertsen, Bolívar, De Mesmaecker, \& Lauwers, 2011; Bolívar, 2010; Rappaport, 1981). Si asumimos la noción de Zimmerman (2000) que una "organización empoderadora" es aquella que abre oportunidades de participación en toma de decisiones, permite compartir responsabilidades y liderazgo, asumiríamos también, por lo tanto, el supuesto de que una imagen de víctima como sujeto en necesidad obstaculizaría las posibilidades de participación. 
VÍCTIMAS EN JUSTICIA RESTAURATIVA: ¿SUJETOS ACTIVOS O EN NECESIDAD? UN ESTUDIO EUROPEO DESDE LA PERSPECTIVA DE OPERADORES SOCIALES

\section{Oportunidades de participación y creencias de profesionales}

En el presente artículo, analizamos las oportunidades de participación para las víctimas de delito, focalizándonos en las creencias de profesionales de JR (quienes ofrecen e implementan los programas de JR) y de apoyo a la víctima (AV), quienes son potenciales derivadores a programas de JR. La pregunta que se desea responder es qué creencias tienen los profesionales de JR y de AV en relación con las víctimas y la JR. Específicamente, interesa identificar en sus discursos elementos que indiquen confianza en los recursos personales de las víctimas para participar activamente en espacios restaurativos, es decir, en un proceso de comunicación con el ofensor y formar parte de la toma de decisiones concernientes a su caso.

\section{Diseño de investigación}

\section{Objetivos del estudio}

El estudio compartido en este artículo forma parte de una investigación mayor cuya principal intención fue investigar la posición de la víctima en programas de justicia restaurativa en Europa. Este artículo se focaliza en uno de sus subestudios, el cual tuvo como objetivo explorar las creencias de los profesionales tanto de JR como de AV sobre victimización criminal y JR y analizar el potencial rol de estas creencias en la participación de víctimas en JR.

\section{Metodología, participantes y procedimientos}

El estudio del cual se deriva el presente artículo fue de tipo exploratorio y descriptivo. Esto significa que la intención no fue generar datos que pudieran ser generalizados a toda la realidad europea. Los programas de JR presentan una diversidad tal (en términos metodológicos, de cobertura, grupo objetivo y relación con el sistema penal) que cualquier intento de generalizar resultados sería improcedente. Más bien, este estudio se concibió como una primera exploración hacia la problematización del rol de los profesionales en la oferta de espacios de participación.
Para diseñar la metodología, se asumió el supuesto de que era relevante incorporar en la muestra tanto profesionales de JR como profesionales de AV, por ser las dos instancias institucionales que suelen tener mayor contacto con víctimas de delitos. Los programas de AV, además, constituyen una de las únicas instancias que podría asegurar un mayor acceso de víctimas a la JR. Su cercanía a las víctimas de delitos no solo le da a los programas de AV un lugar privilegiado para la entrega de información sobre JR, sino que además podría asegurar, a través de este rol, un acceso a JR más equitativo entre víctimas y ofensores ${ }^{2}$.

Esta investigación combinó estrategias cualitativas y cuantitativas de recolección de datos. Si bien ambas metodologías tenían un mismo objetivo (identificar creencias en relación con las víctimas y su participación en JR), ambos grupos de datos tuvieron énfasis distintos. Mientras el estudio cualitativo recolectó impresiones de informantes claves que tenían una perspectiva nacional del fenómeno, el cuantitativo recolectó la percepción de profesionales dedicados a la atención directa de casos. Organizaciones europeas como el Foro Europeo de Justicia Restaurativa (European Forum for Restorative Justice) y Apoyo a la Víctima en Europa (Victim Support Europe) ayudaron a identificar primero programas y luego profesionales de JR y $\mathrm{AV}$, a lo largo y ancho del Continente.

Una vez que informantes potenciales claves fueron identificados, el procedimiento consistió en contactar dichos individuos, generalmente por correo electrónico, con el fin de solicitar su participación en el estudio y/o solicitar su ayuda para ubicar otros miembros de su organización. Todos aquellos que finalmente fueron invitados a formar parte del estudio fueron identificados como informantes claves, ya sea por su conocimiento de la situación de los Programas de JR o AV a nivel nacional (estudio cualitativo) o por su experiencia práctica en ambos programas a nivel local (estudio cuantitativo). Todos los miembros de la muestra fueron, por lo tanto, seleccionados intencionalmente.

2 Las principales instancias derivadoras a JR (jueces y fiscales) tienden a tener mayor contacto con ofensores (Bolívar, 2015; Laxminarayan, 2013). 
Una vez identificados, los potenciales participantes fueron contactados por correo electrónico, explicando el objetivo del estudio y el tipo de participación requerida. Una vez expresada su motivación para participar, se les envió el enlace con la encuesta online o se acordó una fecha de entrevista, dependiendo del caso. La participación en este estudio fue indicada como voluntaria y confidencial.

Cuando JR o AV fueron servicios funcionando con cobertura nacional, todos los entrevistados de un país pertenecieron por lo tanto a la misma organización, pero se promovió su pertenencia a diferentes regiones. Cuando los servicios en cambio eran otorgados por diferentes organizaciones, se aspiró a que los participantes pertenecieran a diferentes instituciones.

\section{Estudio cuantitativo}

El estudio cuantitativo consistió en un cuestionario online (en inglés) creado especialmente para este estudio, que consistió en 64 ítems, combinando preguntas abiertas, de selección múltiple y escalas. Los temas por evaluar incluían marco legal de la JR, contexto institucional, objetivos, entrenamiento de mediadores y facilitadores, descripción del programa (tipo de casos atendidos, características de la preparación, encuentro y seguimiento), tiempos de

TABLA 1

Número de informantes claves identificados, contactados y finalmente incluidos en la muestra, desglosados por país

\begin{tabular}{|c|c|c|c|c|}
\hline \multirow[t]{2}{*}{ País } & \multicolumn{2}{|c|}{ Número de personas claves identificadas } & \multicolumn{2}{|c|}{ Número final de participantes en el estudio } \\
\hline & JR & AV & JR & AV \\
\hline Alemania & 6 & 2 & 6 & 1 \\
\hline Austria & 3 & 1 & 3 & - \\
\hline Bélgica & 3 & 3 & 3 & 3 \\
\hline Bulgaria & 4 & 1 & 1 & - \\
\hline Dinamarca & 4 & 1 & 2 & - \\
\hline Eslovenia & - & 1 & - & - \\
\hline España & 5 & 5 & 3 & 4 \\
\hline Estonia & 2 & 1 & - & - \\
\hline Finlandia & 3 & 2 & 3 & 2 \\
\hline Francia & 3 & 1 & 3 & - \\
\hline Grecia & 4 & - & 4 & - \\
\hline Holanda & 3 & 3 & 3 & 3 \\
\hline Hungría & 6 & 3 & 2 & 3 \\
\hline Irlanda & 3 & 3 & 3 & 3 \\
\hline Italia & 1 & 3 & 4 & - \\
\hline Letonia & 1 & - & 3 & - \\
\hline Lituania & 1 & - & - & - \\
\hline Luxemburgo & 2 & 1 & 2 & - \\
\hline Malta & 2 & 1 & - & 1 \\
\hline Polonia & 1 & 1 & - & - \\
\hline Portugal & 4 & 1 & 1 & 4 \\
\hline Reino Unido ${ }^{1}$ & 19 & 5 & 17 & 5 \\
\hline Republica Checa & 1 & 3 & - & 3 \\
\hline Romania & 1 & - & 3 & 3 \\
\hline Suiza & 3 & 1 & 2 & - \\
\hline Total & 85 & 43 & 68 & 35 \\
\hline
\end{tabular}

Fuente: elaboración propia 
intervención, evaluación de resultados y opiniones en torno a la participación de las víctimas en la justicia restaurativa.

La meta del estudio fue encuestar seis entrevistados por país, es decir, tres provenientes de programas de JR y tres provenientes de programas de $\mathrm{AV}$, siempre y cuando estos programas estuvieran en operación. Efectivamente, dado el grado dispar que tienen los países europeos en términos de desarrollo de programas de JR y de AV (existen países sin o poco desarrollo de JR o AV o con experiencias discontinuadas, incipientes o fragmentadas), no se logró este número en todos los países.

El cuestionario fue contestado por 68 profesionales directamente involucrados en la práctica de la mediación o conferencias familiares y por 35 profesionales de programas de apoyo a la víctima. En la Tabla 1 se puede observar el número de profesionales claves detectados y contactados por país y el número final de participantes.

Los datos se analizaron de manera descriptiva (en términos de frecuencia) y se realizaron, cuando fue pertinente y posible, comparaciones entre profesionales de JR y AV.

\section{Estudio cualitativo}

Este estudio se focalizó en países con fuerte y estable desarrollo de JR o AV, o ambos, ya sea en términos de política pública o larga tradición y experiencia en estas prácticas3.El estudio cualitativo consistió en la realización de 17 entrevistas semiestructuradas a 12 informantes claves de la implementación de JR en sus países y a 5 informantes claves de programas de Apoyo a la Víctima. ${ }^{3}$. Dichos informantes fueron elegidos por poseer un cargo central (a nivel nacional) en sus organizaciones, lo que les permitiría ofrecer una visión general de la implementación del programa. Estos expertos fueron entrevistados telefónica o personalmente.

Durante la entrevista semiestructurada se cubrieron los siguientes temas: características de la implementación del programa, elegibilidad de casos, características del proceso restaurativo y aspectos relacionados con la participación de la víctima. Todas las entrevistas fueron grabadas con la autorización de los entrevistados y posteriormente transcritas. Los datos cualitativos fueron analizados de manera descriptiva, usando el método de codificación axial propuesto por la teoría fundamentada (Charmaz, 2006), con la ayuda del software NVivo.

En suma, en este estudio, participaron un total de 80 profesionales de JR y 40 profesionales de programas de Apoyo a la Víctima los cuales representaron un total de 19 países europeos: Alemania,

3 La lista de países de la Tabla 2, donde se realizaron entrevistas, no es exhaustiva. Razones prácticas y no metodológicas explican la ausencia de algunos países (como por ejemplo, Holanda y Austria).

TABLA 2

Numero de entrevistas semiestructuradas realizadas a coordinadores de programas de JR y AV

\begin{tabular}{lcc}
\hline & País & Número de entrevistados \\
\hline & JR & AV \\
Alemania & 1 & - \\
Bélgica & 2 & 2 \\
España & 2 & - \\
Hungría & - & 1 \\
Irlanda del Norte & 1 & - \\
Noruega & 2 & 1 \\
Portugal & 2 & 1 \\
Reino Unido & 2 & 1
\end{tabular}


Austria, Bélgica, Bulgaria, Dinamarca, España, Finlandia, Francia, Grecia, Holanda, Hungría, Irlanda, Letonia, Luxemburgo, Noruega, Portugal, Reino Unido (incluyendo participantes de Escocia, Irlanda del Norte e Inglaterra), Rumania y Suecia.

\section{Resultados}

Los resultados se han dividido en dos secciones: lo que la JR ofrece (y no) a víctimas de delito y la oferta de mediación. Para hacer más comprensibles los resultados del estudio, se describen sucesivamente datos cuantitativos y cualitativos en cada punto que se debía tratar, cada vez que hubo información disponible de cada conjunto de datos ${ }^{4}$.

\section{JR: lo que ofrece (y no) a víctimas de delitos}

Uno de los temas que se exploraron en la encuesta fue la percepción de los profesionales sobre los beneficios y riesgos de la JR, desde el punto de vista de las víctimas de delito. Este tema se incorporó con el objetivo de detectar las maneras en las que ambas partes conceptualizaban la JR y sus potencialidades para personas con experiencia de victimización criminal. Dos preguntas abiertas indagaban esta temática: "¿Cuáles son los principales beneficios que tiene la justicia restaurativa para las víctimas de delitos?" y "¿Cuáles son los principales riesgos que tiene la justicia restaurativa para las víctimas de delitos?". Las respuestas entregadas fueron categorizadas y enumeradas para calcular su frecuencia ${ }^{5}$.

\section{Beneficios}

Los beneficios mencionados por los profesionales se categorizaron en (a) resultados de la justicia restau-

4 Los contenidos extraídos de entrevistas semiestructuradas son identificadas con letras y números. Así, la entrevista 1 de un profesional del área de la JR es indicada JR:1 y la entrevista 1 de un profesional de Apoyo a la Víctima como AP:1.

5 Dado que cada participante usualmente respondió aludiendo a más de un contenido, las frecuencias obtenidas (indicadas en paréntesis en la Tabla 3) indican el número de personas que se refirieron a ese tema. Por lo tanto, el número total de respuestas no coincide con el número total de participantes en la encuesta, sino con el número total en que cada tema fue mencionado. rativa, (b) efectos del proceso, (c) beneficios relacionados con su metodología y (d) beneficios legales. Estos resultados pueden apreciarse en la Tabla 3.

Respecto de los resultados del proceso, ambos grupos identifican la posibilidad de obtener reparación emocional, el cual se manifiesta en recibir reconocimiento (creído y validado en su estatus de víctima) y recibir disculpas por parte del ofensor. Ambos grupos también reconocen la compensación económica como un resultado deseable para las víctimas.

Profesionales de AV y JR coinciden también en que la JR puede tener efectos psicológicos positivos para las víctimas, especialmente en el ámbito cognitivo y emocional. Al tener la posibilidad de hacer preguntas al ofensor, los efectos psicológicos más importantes son entender lo sucedido y comprender las circunstancias en que el ofensor actuó. Ambos grupos también se refirieron a una serie de emociones positivas que podrían surgir como efecto de la participación de víctimas en JR, como es la disminución de la ansiedad, el sentimiento de culpa, o incrementar la sensación de seguridad y empoderamiento.

También hubo respuestas que indicaron las ventajas de la metodología participativa y de comunicación de la JR. En este aspecto, ambos grupos presentaron una leve diferencia. Para los profesionales de AV, la JR puede aportar con una instancia donde la víctima puede ser escuchada, puede expresarse libremente y tener un rol activo en el proceso. Los profesionales de la JR en cambio, si bien coinciden en todos estos puntos, enfatizaron especialmente el rol no solo activo, sino central de la víctima en la toma de decisiones respecto de cómo resolver el conflicto. Por otro lado, ambos grupos de profesionales enfatizaron también las ventajas relacionales que trae abrir un canal de comunicación entre ambas partes. Las víctimas podrían confrontar al ofensor con las consecuencias del delito y, a través de reunirse personalmente, desmitificarlo (verlo como humano, no como monstruo) e incluso, tener la oportunidad de ayudarlo. Los profesionales de JR agregaron a estos beneficios elementos que se relacionan con la re-construcción de la relación 
Víctimas EN JUSTICIA RESTAURATIVA: ¿SUJETOS ACTIVOS O EN NECESIDAD? UN ESTUDIO EUROPEO DESDE LA PERSPECTIVA DE OPERADORES SOCIALES

TABLA 3

Beneficios del proceso de JR según profesionales de Apoyo a la Víctima y Justicia Restaurativa

\begin{tabular}{|c|c|c|}
\hline & AV & JR \\
\hline \multicolumn{3}{|c|}{ Resultados del proceso } \\
\hline $\begin{array}{l}\text { Reparación } \\
\text { emocional }\end{array}$ & $\begin{array}{l}\text { Recibir disculpas (5) } \\
\text { Reconocimiento (1) }\end{array}$ & $\begin{array}{l}\text { Recibir disculpas (9) } \\
\text { - Reparación emocional } \\
\text { Reconocimiento (5) } \\
\text { - Ser creído y validado }\end{array}$ \\
\hline Reparación material & $\begin{array}{l}\text { Recibir compensación (8) } \\
\text { El cual tiene altas posibilidades de ser } \\
\text { cumplido }\end{array}$ & $\begin{array}{l}\text { Recibir compensación económica (17) } \\
\text { Recibir otras formas de compensación (2) } \\
\text { Pedir al ofensor hacer una tarea especifica }\end{array}$ \\
\hline \multicolumn{3}{|c|}{ Efectos psicológicos del proceso } \\
\hline Efectos cognitivos & $\begin{array}{l}\text { Entender lo sucedido (7) } \\
\text { Entender las circunstancias del ofensor }\end{array}$ & $\begin{array}{l}\text { Entender lo sucedido ( } 30) \\
\text { Posibilidad de hacer preguntas (por qué yo) y recibir } \\
\text { respuestas } \\
\text { Entender las circunstancias del ofensor } \\
\text { Resignificar (2) } \\
\text { Entender que fue no personal }\end{array}$ \\
\hline Efectos emocionales & $\begin{array}{l}\text { Empoderamiento y control (3) } \\
\text { Cierre (2) } \\
\text { Expresar emociones (2) } \\
\text { Dejar la victimización atrás (2) } \\
\text { Sentir seguridad (1) } \\
\text { Ayudar al proceso de recuperación (1) } \\
\text { Disminuir sentimientos de culpa (1) } \\
\text { Perdonar (1) }\end{array}$ & $\begin{array}{l}\text { Expresar emociones libremente (10) } \\
\text { Cierre (6) } \\
\text { Sentir seguridad (5) } \\
\text { Reducir estrés y ansiedad (5) } \\
\text { Experimentar alivio (4) } \\
\text { Empoderamiento y control (4) } \\
\text { Dejar el rol de víctima } \\
\text { Experimentar tranquilidad (1) } \\
\text { Apoyo (1) } \\
\text { Sentir que se ayuda a la sociedad (1) } \\
\text { Desarrollar sentido de autoconfianza (1) } \\
\text { Experimentar sensación de sanación (1) } \\
\text { Experimentar paz (1) }\end{array}$ \\
\hline
\end{tabular}

Beneficios relacionados con aspectos metodológicos de la JR

\begin{tabular}{ll}
\hline Participación & Ser escuchado (4) \\
& Expresar la propia visión del delito (1) \\
& Participar y ser activo en el proceso (3)
\end{tabular}

Tener un rol central en decidir la forma de reparar

el daño causado (9)

Participar y ser activo en el proceso (5)

Ser escuchado (5)

Ser atendido (3)

Oportunidad de recibir información (1)

Tener un rol central en el procedimiento (1)

\begin{tabular}{ll}
\hline Relación con & Confrontar ofensor (5) \\
ofensor & Desmitificar al ofensor (2) \\
& Ayudar al ofensor (1)
\end{tabular}

Desmitificar al ofensor (11)

Confrontar al ofensor (6)

Ventilar frustración y rabia

Reconstruir la relación (en casos de violencia intrafamiliar) (5)

Comunicarse en un ambiente protegido y en paz (4)

Ayudar al ofensor (3)

Conocer al ofensor (2)

Re-balancear la dinámica abusiva (1)

\begin{tabular}{lll}
\hline Beneficios relacionados con su inserción en el sistema penal \\
\hline Sistema judicial & Evitar el juicio (3) & Proceso más rápido (5) \\
& Proceso más rápido (3) & Evitar el juicio (2) \\
& Proceso más económico (2) & Forma menos burocrática de resolver conflictos (2) \\
\hline \multicolumn{2}{c}{ Ausencia beneficios } & \\
\hline \multicolumn{2}{c}{ No hay beneficios en caso de homicidio (1) } \\
\hline
\end{tabular}

$(N=90)$

Fuente: elaboración propia 
entre víctima y ofensor (re-balancear o reconstruir la relación) ${ }^{6}$.

Finalmente, ambos grupos identifican como beneficio la posibilidad de evitar un juicio (cuando JR es entendida como mecanismo de diversificación) y de tener, en cambio, acceso a un proceso más rápido, informal y menos burocrático.

En resumen, los resultados del presente estudio indican que la visión de los profesionales de AV no dista especialmente de la visión de los profesionales de la JR, en términos de los potenciales beneficios para las víctimas. Ambos grupos reconocen beneficios de reparación emocional, reparación material y atribuyen al proceso beneficios cognitivos (de significación, especialmente) y emocionales (disminución de síntomas negativos, como el miedo). Ambos grupos también reconocen aspectos de relevancia en términos de las ventajas del proceso, en su relación con el sistema penal y las potencialidades de participación de la víctima. Sin embargo, algunos profesionales de JR mencionaron también la posibilidad de tener un rol clave en la manera de resolver la forma en que el daño puede ser reparado.

\section{Riesgos}

En términos de riesgos, en el análisis se pudieron distinguir factores de riesgo asociados a los actores del proceso (mediador, víctima y ofensor) y a los momentos de la intervención (derivación, preparación, encuentro propiamente tal y acuerdo reparatorio).

En relación con los actores del proceso, y en particular, con el mediador, ambos grupos coinciden en que los riesgos pueden provenir de un mediador con insuficiente conocimientos o entrenamiento, o de un facilitador con tendencia a sesgar su intervención hacia el ofensor, no prestando suficiente atención a la víctima. Ambos grupos coincidieron también en que el ofensor podría ser fuente de riesgos, especialmente cuando no asume responsabilidad, tiene motivación por beneficios judiciales o no cumple con el acuerdo

6 El tipo de contenido involucrado en estas respuestas hace pensar que estos participantes se referían específicamente a casos de violencia intrafamiliar. y, por lo tanto, su conducta no coincide con la actitud demostrada en el encuentro restaurativo.

Respecto de los factores de riesgo provenientes de la víctima, los profesionales de AV creen que ella puede no estar preparada psicológicamente o ser vulnerable. También puede desarrollar sentimientos de venganza como consecuencia de su encuentro con el ofensor. Los profesionales de JR concuerdan con estos puntos, pero agregan además sus preocupaciones por víctimas en posición de vulnerabilidad en relación con el ofensor, verse obligada a confrontar temas ya cerrados, no contar con figuras de apoyo durante el proceso y ser presionada a participar para evitar el tribunal. También se visualizaron, por parte de ambos grupos, riesgos de la relación víctimaofensor, como victimización por desbalances de poder y manipulación del ofensor hacia la víctima.

Las etapas de la intervención también podrían acarrear riesgos. Los puntos de mayor coincidencia tienen que ver con insuficiente preparación y manejo de expectativas, instrumentalización de la víctima en el encuentro restaurativo y baja o nula compensación económica. A esto, los profesionales de AV agregan el riesgo de que el delito sea minimizado con el proceso restaurativo, minimización del delito, experiencias de presión (ya sea para aceptar disculpas o la solución) y el de que las preguntas de las víctimas no puedan ser respondidas. Los profesionales de JR también visualizan riesgos en la fase de derivación (derivación tardía), deficiente acceso a información legal u otras para decidir sobre su participación, deficiente evaluación de riesgos y falta de coordinación con servicios de AV. En ambos grupos hubo uno o dos participantes que indicaron que un proceso facilitado en óptimas condiciones no debería significar riesgo alguno para la víctima.

\section{La oferta de mediación}

Además de ítems que buscaban una descripción de los procedimientos de la JR, el cuestionario incluyó ítems que sondeaban opiniones de los profesionales de JR y de oficinas de Apoyo a la Víctima en relación con las personas consideradas "idóneas" para un proceso restaurativo. De esta manera, se identificarían creencias que podrían constituirse ya sea 
VÍCTIMAS EN JUSTICIA RESTAURATIVA: ¿SUJETOS ACTIVOS O EN NECESIDAD? UN ESTUDIO EUROPEO DESDE LA PERSPECTIVA DE OPERADORES SOCIALES

TABLA 4

Riesgos del proceso de JR según profesionales de Apoyo a la Víctima y Justicia Restaurativa

\begin{tabular}{|c|c|c|}
\hline $\begin{array}{l}\text { Fuentes de ori- } \\
\text { gen del riesgo }\end{array}$ & AV & $\mathrm{RJ}$ \\
\hline \multicolumn{3}{|c|}{ Actores en el proceso } \\
\hline Mediador & $\begin{array}{l}\text { Mediador sin entrenamiento/experiencia (2) } \\
\text { Incapacidad para escuchar a la víctima (1) }\end{array}$ & $\begin{array}{l}\text { Mediador sin entrenamiento/ experiencia (3) } \\
\text { Mediador sesgado hacia el ofensor (1) } \\
\text { Dar mucha responsabilidad a la víctima para que } \\
\text { encuentre una solución (1) }\end{array}$ \\
\hline Ofensor & $\begin{array}{l}\text { Falta de responsabilización por parte del ofensor } \\
\text { (3) } \\
\text { Motivación del ofensor (2) } \\
\text { - Evitar juicio } \\
\text { Disculpas sin correlato conductual (1) } \\
\text { - No cambia } \\
\text { - No cumple acuerdo }\end{array}$ & $\begin{array}{l}\text { Falta de remordimiento (7) } \\
\text { Falta de colaboración por parte del ofensor (4) } \\
\text { Ofensor no cumple con acuerdo (3) } \\
\text { Motivación del ofensor (2) } \\
\text { - Evitar el juicio } \\
\text { - Recibir otros beneficios }\end{array}$ \\
\hline Víctima & $\begin{array}{l}\text { No estar preparada psicológicamente (1) } \\
\text { Ser vulnerable (1) } \\
\text { Desarrollar deseos de venganza (1) }\end{array}$ & $\begin{array}{l}\text { Causar mayores sentimientos negativos en rela- } \\
\text { ción con el delito (1) } \\
\text { En casos de desbalance de poder: no ser capaces } \\
\text { de decir/hablar por miedo (2) } \\
\text { Verse en la necesidad de confrontar temas que ha } \\
\text { preferido olvidar (2) } \\
\text { Afectarse o estresarse por encontrarse con el } \\
\text { ofensor (2) } \\
\text { Sobreestimar los propios recursos (1) } \\
\text { No ser suficientemente fuertes para enfrentar el } \\
\text { proceso (1) } \\
\text { Aceptar solo para evitar el tribunal (1) } \\
\text { Falta de figuras de apoyo (1) }\end{array}$ \\
\hline Relación & $\begin{array}{l}\text { Continuar el contacto con ofensor (1) } \\
\text { Victimización por desbalances de poder (1) } \\
\text { La víctima puede ser manipulada por ofensor (1) }\end{array}$ & La víctima puede ser manipulada por ofensor (3) \\
\hline \multicolumn{3}{|c|}{ Etapas de la intervención } \\
\hline Derivación & & Demora en derivar a justicia restaurativa (1) \\
\hline Preparación & $\begin{array}{l}\text { Falta de preparación (5) } \\
\text { Deficiente manejo de expectativas (4) } \\
\text { Presión para participar (1) }\end{array}$ & $\begin{array}{l}\text { Falta de preparación (4) } \\
\text { Bajo manejo de expectativas (11) } \\
\text { Deficiente acceso a orientación legal (1) } \\
\text { Ausencia de otras fuentes de información para } \\
\text { evaluar pros y contras (1) } \\
\text { Deficiente evaluación de riesgos (1) }\end{array}$ \\
\hline $\begin{array}{l}\text { Encuentro víc- } \\
\text { tima-ofensor }\end{array}$ & $\begin{array}{l}\text { Instrumentalización (1) } \\
\text { Presión a aceptar disculpas (1) } \\
\text { Minimización el delito (sanción no es significa- } \\
\text { tiva) (1) } \\
\text { Presión a aceptar una solución injusta (1) } \\
\text { Centrada en un resultado rápido (1) }\end{array}$ & $\begin{array}{l}\text { Caso que no prospera y que por lo tanto no tiene } \\
\text { resultado (1) } \\
\text { Proceso enfocado a las necesidades del ofensor } \\
\text { (1) } \\
\text { Falta de coordinación con servicios de atención a } \\
\text { víctima (1) }\end{array}$ \\
\hline
\end{tabular}

\begin{tabular}{lll}
\hline $\begin{array}{l}\text { Acuerdo de } \\
\text { reparación }\end{array}$ & $\begin{array}{l}\text { Objetivos no logrados (2) } \\
\text { Obtener baja compensación (1) } \\
\text { Resultado insatisfactorio (2) } \\
\text { - Preguntas no son respondidas }\end{array}$ & $\begin{array}{l}\text { Obtener baja compensación (2) } \\
\text { No obtener compensación (1) }\end{array}$ \\
\hline $\begin{array}{l}\text { Un proceso bien realizado previene todos los } \\
\text { riesgos (1) }\end{array}$ & $\begin{array}{l}\text { Una buena preparación previene todos los ries- } \\
\text { gos (2) }\end{array}$ \\
\hline
\end{tabular}

$(N=90)$

Fuente: elaboración propia 
en facilitadores u obstaculizadores para el acceso de víctimas a la información sobre programas de JR.

\section{El ofrecimiento de JR y sus posibles efectos}

Uno de los aspectos claves para determinar las posibilidades de participación de víctimas en instancias de JR es determinar a quién se considera se debe ofrecer el servicio y por qué. Es decir, si desde el punto de vista de las creencias de los profesionales, debieran existir determinados filtros para invitar a víctimas a participar y basados en qué criterios.

Más de un $50 \%$ de los participantes, tanto del grupo de JR (56\%) como de AV (59\%), estuvieron en desacuerdo o muy en desacuerdo con la frase "El ofrecimiento de mediación es dañino para quien lo rechaza". A pesar de esta mayoría, los datos cualitativos sugieren que en la práctica, la JR no se ofrece espontáneamente. Dos de los informantes claves que trabajan en $\mathrm{AV}$ desde una perspectiva nacional comentaron que los funcionarios de AV no suelen informar a las víctimas sobre JR, a menos que estas, espontáneamente, hablen de su motivación por encontrarse con el ofensor.

Un segundo tema abordado fue la manera de ofrecer el servicio, es decir, si la víctima debe ser contactada antes o después de contactado el ofensor. Nuestros resultados indican que si bien $50.7 \%$ de los profesionales de JR estaban de acuerdo o muy de acuerdo con la frase "Si la víctima es contactada antes del ofensor, y este rechaza JR, la victima puede sufrir victimización secundaria", los profesionales de AV mostraron mayor distribución en sus respuestas (solo un $42.8 \%$ estuvo de acuerdo o muy de acuerdo). La frase "Si la víctima es contactada después del ofensor, esta puede pensar que el programa tiene un sesgo a favor del ofensor" fue apoyada por un $62 \%$ de profesionales de $\mathrm{AV}$, pero solo apoyada por un $24.8 \%$ de facilitadores de JR. En otras palabras, al comparar los promedios obtenidos en cada ítem, los profesionales de $\mathrm{AV}$ parecen estar más preocupados de los efectos que causaría en la víctima ser invitada después del ofensor que los participantes de JR (U $=1.474 p=0.013$ ).

El estudio cualitativo sin embargo mostró énfasis distintos. Dos de los entrevistados de AV enfatizaron el riesgo de victimización secundaria, cuando el ofrecimiento a la víctima toma lugar antes de clarificar la motivación del ofensor. El ofensor puede cambiar de opinión sobre participar en JR (AV:4) o su negativa puede llevar a pensar a la víctima que el ofensor es quien controla, una vez más, la situación (AV:3). Por el contrario, si bien muchos profesionales de JR no parecían tener una preferencia específica de cómo comenzar un procedimiento restaurativo, un par de ellos resaltaron la relevancia de comenzar por la víctima en casos graves para dar una señal de reconocimiento de su estatus de víctima (JR:8) o en casos de violencia doméstica, para evitar presiones por parte del ofensor en el proceso de decidir si participar o no (JR:3).

TABLA 5

Opiniones acerca del ofrecimiento de JR a víctimas de delito separado en profesionales de JR y de AV

\begin{tabular}{lcccccc}
\hline & \multicolumn{3}{c}{ JR } & & & AV \\
& $\begin{array}{c}\text { Desacuerdo } \\
(\%)\end{array}$ & $\begin{array}{c}\text { Indeciso } \\
(\%)\end{array}$ & $\begin{array}{c}\text { Acuerdo } \\
(\%)\end{array}$ & $\begin{array}{c}\text { Desacuerdo } \\
(\%)\end{array}$ & $\begin{array}{c}\text { Indeciso } \\
(\%)\end{array}$ & $\begin{array}{c}\text { Acuerdo } \\
(\%)\end{array}$ \\
\hline $\begin{array}{l}\text { El ofrecimiento de mediación es dañino para } \\
\text { quien lo rechaza. }\end{array}$ & 56.5 & 24.6 & 13 & 59 & 25 & 8.6 \\
$\begin{array}{l}\text { Si la víctima es contactada antes del } \\
\text { ofensor, y este rechaza JR, esta puede sufrir } \\
\text { victimizacion secundaria. }\end{array}$ & 26.1 & 20.3 & 50.7 & 34.2 & 22.9 & 42.8 \\
$\begin{array}{l}\text { Si la víctima es contactada después del } \\
\text { (1) }\end{array}$ & 40.6 & 24.6 & 24.8 & 20 & 17.1 & 62.8
\end{tabular}
ofensor, esta puede pensar que el programa tiene un sesgo a favor del ofensor.

$N=99$

Fuente: elaboración propia 
En síntesis, los datos recolectados indican que no existe una perspectiva única en relación con el ofrecimiento de mediación y el efecto que este pueda tener. Tanto en profesionales de JR como de AV hay preocupaciones sobre los efectos que podría tener el ofrecimiento de JR a la víctima, ya sea antes de conocer la opinión del ofensor o después de que se ha trabajado con él. Además, a pesar de que una mayoría cree que el ofrecimiento de JR no es dañino en sí mismo, información obtenida en las entrevistas indica que los profesionales de AV tienden a no mencionar el tema espontáneamente.

\section{El rol del profesional en la} decisión de participar

El presente estudio también exploró las creencias de los entrevistados acerca de las atribuciones que estos otorgaban al profesional para decidir la procedencia de un caso para un proceso de JR. En otras palabras, qué tan profesionalizada veían esta intervención y qué rol daban a los usuarios en general (y a las víctimas en particular) en esta decisión.

En general, sobre el $70 \%$ de los encuestados (tanto de JR como de AV) daban al profesional de JR (facilitador o mediador) un rol central en la decisión de proceder o no con JR en determinados casos, aun cuando esta decisión esté en contra de la voluntad de víctima y ofensor (Tabla 6).

Al preguntar de manera abierta en qué situaciones mediadores o facilitadores podrían tomar esta decisión, los encuestados mencionaron: falta de toma de responsabilidad por parte del ofensor, víctima vulnerable o furiosa, situaciones de amenaza, miedo, riesgo o presión a participar. Expectativas irrealistas y la sugerencia de un terapeuta a no proceder, también serían razones para descontinuar un proceso.

El estudio cualitativo entregó más matices a esta temática. La mayoría de los entrevistados de JR indicaron que la decisión de detener un proceso por iniciativa del mediador y en contra de la voluntad de las partes era una situación excepcional. La principal razón, explicaron, es que los dueños del conflicto son las partes y son ellas quienes deben decidir, conociendo en detalle las circunstancias en que se dará su participación. Por ejemplo, la víctima tiene el derecho a elegir si, conociendo la falta de aceptación de responsabilidad por parte del ofensor, aún prefiere encontrarse con él y confrontarlo con el daño causado por el delito:

Si nosotros vemos que el ofensor no es apropiado [para JR], la víctima debe decidir si él es apropiado o no (...) si el ofensor no se siente culpable esto probablemente no es apropiado [para JR], pero si la víctima aún quiere ir, es ella quien debe decidir. (JR:3)

Para uno de los entrevistados dos excepciones a esta regla son niños víctimas o personas con serios problemas de salud mental.

Exceptuando por estas dos situaciones, el mediador no puede detener un proceso por su cuenta. Más bien este puede recomendar la suspensión cuando se visualiza que las expectativas de ambas partes,

\section{TABLA 6}

Opiniones acerca de casos y víctimas inapropiadas para mediación

\begin{tabular}{lcc}
\hline $\begin{array}{l}\text { ¿Puede un mediador/facilitador considerar un caso inadecuado } \\
\text { para JR, a pesar de la voluntad de las partes para seguir adelante? }\end{array}$ & $\begin{array}{c}\text { RJ (Porcentaje de } \\
\text { respuestas afirmativas) }\end{array}$ & $\begin{array}{c}\text { VS (Porcentaje de } \\
\text { respuestas afirmativas) }\end{array}$ \\
\hline $\begin{array}{l}\text { Un caso podría considerarse inapropiado para JR a pesar de la } \\
\text { voluntad de ambas partes de participar. }\end{array}$ & 91.3 & 77 \\
$\begin{array}{l}\text { Una víctima podría considerarse inapropiada para JR a pesar de } \\
\text { su voluntad para participar. }\end{array}$ & 76.8 & 76.4 \\
$N=103$ & & \\
Fuente: elaboración propia & &
\end{tabular}


y lo que cada uno desea poner en el proceso, no coinciden. (JR: 9)

La decisión de un mediador o facilitador de detener un proceso de JR en contra de la voluntad de las partes puede más bien ser el reflejo de diferentes situaciones:

A. El temor del mediador/facilitador a manejar un conflicto difícil.

En los primeros tiempos del servicio algunos facilitadores enfrentaban a un ofensor muy agresivo y decían mucho más fácilmente 'yo no continúo', pero ahora los facilitadores tienen más entrenamiento en cómo trabajar con jóvenes agresivos (...). Ahora tenemos muy pocos casos en los que no hacemos conferencias. Si hay temas de salud mental podemos decir es difícil, pero actualmente podemos trabajar con cada joven ofensor no importa cuán difícil él o ella sea. Porque todo se trata de [hacer] una buena preparación. También en términos de preparar a la víctima y decir 'esta persona tiene dificultades para expresarse, puede no reaccionar como esperas que reaccione'. Cuando un facilitador me dice 'no puedo hacer esta conferencia' yo siempre digo "ite preocupa que no puedas hacerlo?' Yo creo que es el problema del facilitador quien está asustado. No podemos limitar la participación [de las partes] en la conferencia porque somos nosotros quienes no podemos ayudarlos. (JR:2)

B. El reflejo de preconcepciones acerca de lo que debe o no ser una víctima de delito.

Los profesionales no pueden ser paternalistas, y aceptar la decisión de las víctimas a participar, así como no dar por asumido cómo debe pensar y comportarse una víctima. (JR:7)

C. La tendencia de profesionales a tomar decisiones en nombre de las víctimas, por (creer) saber lo que es bueno para ellas.

Somos buenos colaboradores con AV, pero el problema que tenemos es que tenemos mucha resistencia, [ellos dicen] la víctima no está lista para esto, y yo pienso icómo sabes eso?, son ellos [los profesionales de AV] los que deciden si la víctima está lista o no, eso yo no lo puedo entender (...). La gente no entiende si la víctima necesita hacer eso [mediación], es difícil de entender. Hay un problema de traducción. Tenemos que traducir esto a los demás. (JR:8)

E: ¿Qué significa cuando se dice 'esta víctima no está preparada'?

R: Para ser honesta, no lo sé. Yo creo que nuestros colegas de JR tienen razón: nosotros sólo pensamos en ellos cuando la víctima menciona su interés por comunicarse con el ofensor, pero nosotros no iniciamos esto (...), creo que el foco de AV es la relación de la víctima con la corte, no con comunicarse con el ofensor. (AV:4)

D. La dificultad para visualizar la posibilidad de participación de víctimas de delitos serios en JR, especialmente de delitos sexuales.

Los profesionales de AV estamos sobreprotegiendo a las víctimas, somos más escépticos especialmente en casos de delitos serios, especialmente en casos de víctimas de violación que quieren reunirse con su ofensor. (AV:3)

En suma, nuestras exploraciones nos llevan a concluir que existe la visión, tanto entre los profesionales de JR como de AV, de que la opinión profesional es decisiva a la hora de considerar la adecuación de un caso para JR, especialmente en casos graves.

El perfil de los casos, sin embargo, no sería el único factor que explicaría la decisión de viabilidad. Otro factor determinante serían las creencias que tienen los operadores sociales sobre lo que significa 'ser víctima de delito' y los temores que pueden aparecer al enfrentarse casos difíciles.

Los profesionales de JR entienden que una de sus atribuciones en tanto facilitadores es la posibilidad de suspender un proceso por criterio propio y en contra de la voluntad de las partes. Sin embargo, esta sería una medida excepcional dado el rol protagónico que deben tener las partes en la decisión. 


\section{Víctimas vulnerables $y$} víctimas traumatizadas

Nuestro cuestionario también exploró las creencias que tenían los encuestados sobre las posibilidades de víctimas traumatizadas o vulnerables en proceso de JR. Como se puede ver en Tablas 7 y 8, los profesionales de JR y $\mathrm{AV}$ tendieron a diferir en su evaluación de víctimas vulnerables o traumatizadas como participantes adecuadas para procesos de JR. Mientras, en promedio, los encuestados de AV tendieron a rechazar la opción de JR para ambos grupos de victimas, los profesionales de JR la apoyaron ("Víctimas vulnerables no pueden participar": $\mathrm{U}=1.568, p=0.001$; "Víctimas traumatizadas no pueden participar": $\mathrm{U}=1.494, p=0.008$ ).
Un $53 \%$ de profesionales de JR estuvieron en desacuerdo o muy en desacuerdo con la frase "las víctimas traumatizadas no pueden participar en instancias de JR a menos que sean evaluadas por un profesional" y un $63.8 \%$ estuvo en desacuerdo con la misma frase, pero en relación con víctimas vulnerables. Lo profesionales de $\mathrm{AV}$ tendieron a estar de acuerdo con la JR en casos de victimas traumatizadas (45.7\%) pero a estar en desacuerdo en casos de victimas vulnerables (51.4\%). La idea de involucramiento de personas de la red familiar u otros significativos como requisito sine qua non para la participación de víctimas traumatizadas o vulnerables recibió más apoyo por parte de $\mathrm{AV}(48.6 \%$ y $51.4 \%$, respectivamente) que por parte de profesionales de JR (33.3 \% y $37.3 \%$, respectivamente).

TABLA 7

Creencias sobre las posibilidades de participación de víctimas traumatizadas en JR desglosadas por profesionales de JR y AV

\begin{tabular}{lcccccc}
\hline & \multicolumn{3}{c}{ JR } & \multicolumn{3}{c}{ AV } \\
\hline & $\begin{array}{c}\text { Desacuerdo } \\
\%\end{array}$ & $\begin{array}{c}\text { Indeciso } \\
\%\end{array}$ & $\begin{array}{c}\text { Acuerdo } \\
\%\end{array}$ & $\begin{array}{c}\text { Desacuerdo } \\
\%\end{array}$ & $\begin{array}{c}\text { Indeciso } \\
\%\end{array}$ & $\begin{array}{c}\text { Acuerdo } \\
\%\end{array}$ \\
\hline $\begin{array}{l}\text { Las víctimas traumatizadas no pueden } \\
\text { participar en instancias de JR. }\end{array}$ & 53 & 20.3 & 23.1 & 34.3 & 17.1 & 48 \\
\hline $\begin{array}{l}\text { Las víctimas traumatizadas no pueden } \\
\text { participar en instancias de JR a menos que } \\
\text { sean evaluadas por un profesional. }\end{array}$ & 46.3 & 24.6 & 24.6 & 45.7 & 17.1 & 37.7 \\
$\begin{array}{l}\text { Las víctimas traumatizadas no pueden } \\
\text { participar en instancias de JR a menos que } \\
\text { sean acompañadas por una figura de apoyo. }\end{array}$ & 33.3 & 30.4 & 33.3 & 25.7 & 25.7 & 48.6 \\
\hline
\end{tabular}

Fuente: elaboración propia

TABLA 8

Creencias sobre las posibilidades de participación de víctimas vulnerables en JR desglosadas por profesionales de JR y AV

\begin{tabular}{lcccccc}
\hline & \multicolumn{3}{c}{ JR } & \multicolumn{3}{c}{ AV } \\
\hline & $\begin{array}{c}\text { Desacuerdo } \\
\%\end{array}$ & $\begin{array}{c}\text { Indeciso } \\
\%\end{array}$ & $\begin{array}{c}\text { Acuerdo } \\
\%\end{array}$ & $\begin{array}{c}\text { Desacuerdo } \\
\%\end{array}$ & $\begin{array}{c}\text { Indeciso } \\
\%\end{array}$ & $\begin{array}{c}\text { Acuerdo } \\
\%\end{array}$ \\
\hline $\begin{array}{l}\text { Las víctimas vulnerables no pueden } \\
\text { participar en instancias de JR. }\end{array}$ & 63.8 & 24.6 & 8.7 & 37.2 & 20 & 42.2 \\
\hline $\begin{array}{l}\text { Las víctimas vulnerables no pueden } \\
\text { participar en instancias de JR a menos que } \\
\text { sean evaluadas por un profesional. }\end{array}$ & 69.6 & 15.9 & 11.5 & 34.3 & 14.3 & 51.4 \\
$\begin{array}{l}\text { Las víctimas vulnerables no pueden } \\
\text { participar en instancias de JR a menos que } \\
\text { sean acompañadas por una figura de apoyo. }\end{array}$ & 36.2 & 21.7 & 37.6 & 20 & 28.6 & 51.4 \\
\hline
\end{tabular}

Fuente: elaboración propia 
La mayoría de los encuestados de JR plantearon que la JR debería ser ofrecida a todas las víctimas, indistintamente el tipo de delito (56 \%) y momento del sistema penal (59\%), e incluso son de la opinión que la JR puede ofrecer mayores beneficios a víctimas de delitos graves (56\%). Sin embargo, los profesionales de Apoyo a la Víctima (quienes son importantes instituciones derivadores a programas de JR) tienen opiniones más divididas al respecto. El 45 \% está en desacuerdo con una oferta abierta a todas las víctimas independientemente del tipo de caso y el 53 \% está en desacuerdo con ofrecer JR en cualquier momento del sistema penal. Además, $78 \%$ no cree que la JR funcione mejor en casos de delitos graves y $63 \%$ tiende a creer que JR, cuando es aplicada a delitos menores, debería focalizarse principalmente en compensación económica (vs. $78 \%$ de profesionales de JR que está en desacuerdo con este punto y cree, a su vez, que en estos casos el proceso de comunicación es tan importante como en delitos graves).

Las entrevistas a informantes claves también dieron luces en este tema. Una pregunta por descifrar es qué se entiende por víctima vulnerable o traumatizada. Una opción es que se tienda a equiparar las consecuencias de la victimización con indicadores de vulnerabilidad.

Eso lo escuchamos a menudo. Que la víctima está muy furiosa o muy triste, o muy... muchas emociones parecen ser un mal indicador. Cuando nosotros pensamos precisamente lo contrario, porque todas esas emociones pueden ser discutidas en mediación. No veo una razón para no discutirlo con la víctima. Simplemente como una oferta, como una posibilidad, [luego] queda en manos de la víctima decidir qué hacer. (JR:8)

Para algunos profesionales de JR estar en presencia de una víctima vulnerable o traumatizada, pero dispuesta a JR no significa detener el proceso, sino realizar una detallada preparación (JR:1; JR:7) tomando medidas de resguardo, como incluir e involucrar a los miembros de la red cercana de la víctima (JR:1) o definir cuidadosamente lo que las personas desean obtener del proceso.

En una primera entrevista podemos ver fácilmente si la víctima esta traumatizada, pero si ella realmente quiere ir a mediación nunca lo haremos sin pedir la ayuda de personas de su red cercana o de terapeutas, esto tiene que ser en paralelo, si vemos que la víctima necesita cualquier tipo de ayuda nosotros derivamos, tenemos una buena red de apoyo. (JR:3)

En este país lo que ves muy frecuentemente es que la gente asume supuestos acerca de lo que la gente quiere de JR, porque lo que las víctimas pueden querer de JR puede ser muy variado. (JR:7)

Para otros entrevistados (tanto de JR como AV), en cambio, estar en presencia de víctimas muy traumatizadas o vulneradas implica detener el proceso

TABLA 9

Creencias sobre a qué víctimas ofrecer JR, desglosadas por profesionales de JR y AV

\begin{tabular}{lcccccc}
\hline La JR debe ser ofrecida a todas las víctimas.... & \multicolumn{3}{c}{ JR } & \multicolumn{3}{c}{ AV } \\
& $\begin{array}{c}\text { Desacuerdo } \\
\%\end{array}$ & $\begin{array}{c}\text { Indeciso } \\
\%\end{array}$ & $\begin{array}{c}\text { Acuerdo } \\
\%\end{array}$ & $\begin{array}{c}\text { Desacuerdo } \\
\%\end{array}$ & $\begin{array}{c}\text { Indeciso } \\
\%\end{array}$ & $\begin{array}{c}\text { Acuerdo } \\
\%\end{array}$ \\
\hline $\begin{array}{l}\text {.. independientemente de sus circunstancias } \\
\text { personales. }\end{array}$ & 27.5 & 10.1 & 59.4 & 51.5 & 11.4 & 37.2 \\
\hline ... independientemente del tipo de delito. & 26.1 & 11.6 & 56.5 & 42.8 & 14.3 & 42.9 \\
\hline $\begin{array}{l}\text {..independientemente del momento del } \\
\text { sistema penal. }\end{array}$ & 23.2 & 13 & 59.4 & 54.3 & 8.6 & 37.1 \\
\hline
\end{tabular}

Fuente: elaboración propia 
de JR ya que "tenemos que saber que lo que hacemos es seguro para la víctima" (JR:6), especialmente en casos de desbalances de poder como víctimas menores de edad (AV:4).

En resumen, nuestros datos indican que los programas de AV y JR se aproximarían a la víctima desde perspectivas diferentes. Los profesionales de AV tendieron a enfatizar la opinión profesional para para determinar la viabilidad de un caso, la importancia de la participación de redes de apoyo como requisito de participación de la víctima vulnerable o traumatizada y la visualización de la JR como una estrategia para determinados tipos de casos (delitos menores o de mediana gravedad). Los profesionales de JR, en cambio, tendieron a presentar, aunque no de manera unánime, una opinión opuesta. Sus respuestas hacen pensar en una postura que promueve la JR como una oferta abierta a todo tipo de casos y víctimas. Algunos entrevistados incluso consideraron vulnerabilidad o riesgo no como una limitación para la participación, sino como un aspecto a trabajar en el proceso restaurativo.

\section{Conclusiones y discusión: desafíos de la participación de víctimas en el ámbito de justicia}

El presente estudio tiene importantes limitaciones metodológicas que se deben explicitar antes de exponer las conclusiones. En primer lugar, los participantes de la muestra comparten un sesgo: el idioma de recolección de datos fue el inglés y por lo tanto participaron solo aquellos que pudieron leer y contestar nuestra encuesta (o responder nuestra entrevista). En segundo lugar, el bajo número de participantes logrados en la submuestra de profesionales de AV puede indicar dos cosas: a) que las estrategias de identificar estos profesionales no fueron exitosas o b) que solo aquellos que creían saber de JR, el principal tema de la encuesta y entrevista, aceptaron nuestra invitación. Estos sesgos tienen una relevancia primordial para contextualizar y problematizar los resultados, ya que están indicando un proceso de autoselección de la muestra.

En segundo lugar, el $N$ de la muestra también implica importantes limitaciones metodológicas, especialmente para el estudio cuantitativo. Si bien la generalización estadística no fue parte de nuestro objetivo, otro tipo de muestreo podría haber sido de utilidad. Por ejemplo, una muestra estratificada podría dar luces de los discursos que tienen profesionales que trabajan en diferentes tipos de programas de AV.

Dicho esto, nuestras principales conclusiones se relacionan con tres aspectos: oferta de JR, criterios de adecuación para participar en JR y responsabilidad del ofensor.

\section{Ofrecimiento de justicia restaurativa para víctimas de delitos}

Los datos indican que, si bien tanto los profesionales de JR como los de AV están de acuerdo con que el sólo ofrecimiento de JR a víctimas de delitos no tendría un impacto negativo, queda en evidencia también que, en la práctica, la información sobre JR parece no llegar tan fácilmente a las víctimas de delito. Esta contradicción parece estar demostrando que el tema es aún un asunto no resuelto en la práctica. La declaración de la posición de la víctima en el proceso de mediación realizada por la organización European Forum for Victim Services (2003) hace evidente los temores que prevalecían hace algunos años y que, a la luz de nuestra evidencia, parece aun prevalecer: "la invitación de reunirse con el ofensor es una intervención poderosa que puede imponer responsabilidades indeseadas a la víctimas. Víctimas que rechazan participar pueden sentirse culpable o temer venganza por parte del ofensor" (2004, p. 4)

Como ya se ha mencionado en publicaciones previas, la falta de información sobre programas de JR puede ser, en sí misma, una fuente de victimización. Evidencia empírica sugiere la importancia que tiene para las víctimas de delitos tener información sobre la posibilidad de JR y que estos programas estén disponibles y accesibles (Bolívar, 2012a; Wemmers \& Van Camp, 2011). Las personas afectadas por un delito podrían, al tener información sobre la existencia de estos programas, decidir cuándo dar inicio a un proceso restaurativo, pudiendo, en otras palabras, participar del proceso de toma de 
decisiones desde el inicio. Esta necesidad es relevante tomando en cuenta que a) los tiempos de la víctima no necesariamente se relacionan con los tiempos del sistema judicial (Lauwaert, 2015) y b) las víctimas pueden percibir, cuando hay beneficios legales asociados y la solicitud se inicia desde el ofensor, que los procesos restaurativos, en vez de ser neutrales, están orientados a mejorar el estatus legal del ofensor (Bolívar, 2012b).

\section{Criterios de selección para participar en justicia restaurativa}

Mientras los defensores de la JR insisten en la centralidad del concepto de empoderamiento como meta y principio de la JR (Barton, 2000; Larson \& Zehr, 2007), otros autores acentúan la importancia de ideas como elegibilidad y adecuación ("eligibility" y "suitability") (Centre for Innovative Justice, 2014). En otras palabras, existe una tensión en la literatura entre un enfoque de competencias y un enfoque de carencias, lo que lleva de corolario una tensión entre devolver el conflicto a las partes y profesionalizar la decisión de seleccionar casos idóneos para la JR. Ya se ha discutido previamente cómo el sistema judicial se ha transformado en el principal filtro de acceso a la JR (Bolívar, 2012) y, en este artículo, cómo las políticas públicas han resaltado la relevancia de nociones como evaluación de riesgo y resguardos. El Centre for Innovative Justice (2014), por ejemplo, plantea un proceso de selección de casos en dos etapas diferentes: elegibilidad y adecuación. Elegibilidad es la selección de casos de acuerdo a determinados criterios objetivos (como tipo de delito) y adecuación implica un proceso de evaluación más subjetivo que se puede llevar a cabo a través de instrumentos o entrevistas clínicas. Para ellos, importantes criterios de elegibilidad son un ofensor que tome responsabilidad y una víctima que participa en complete libertad y conocimiento de sus derechos.

Esto no significa que la JR no deba evaluar riesgos ni tomar resguardos. Por el contrario, seguridad mental y física es un imperativo ético de la intervención de JR (Organización de las Naciones
Unidas, 2006). El carácter "empoderador" o "limitador" de una evaluación de riesgo parece tener que ver, en cambio, con la utilización que se haga de él. Según lo comentado por algunos de nuestros entrevistados, y acorde a una filosofía empoderadora, la detección de riesgos no necesariamente debería limitar el acceso a JR de personas con voluntad de asistir. Más bien, permitiría elaborar estrategias que garanticen un proceso restaurativo seguro para todos sus participantes. Mercer \& Sten (2015)

\section{Responsabilidad del ofensor vs. las} necesidades de las víctimas

Si bien la toma de responsabilidad de un ofensor es un reconocido criterio de elegibilidad (Organización de las Naciones Unidas, 2006), estudios recientes en el ámbito de los delitos sexuales indican que procesos de JR pueden llevarse a cabo en casos de ofensores con dificultades para aceptar responsabilidad bajo la condición de que la víctima, conociendo esta situación, aún esté dispuesta a reunirse con el ofensor. Aun en estas circunstancias, mediadores han observado procesos beneficiosos para ambas partes (Mercer \& Sten, 2015).

La conclusión final es que a pesar de la centralidad de las nociones de participación y empoderamiento en la JR, las creencias de profesionales, y en particular de aquellos que tienen la posibilidad de informar y derivar (como son los servicios de $\mathrm{AV})$, parece estar dificultando seriamente el acceso de víctimas a programas de JR. Estas creencias sitúan y tipifican a la víctima como un individuo en necesidad y vulnerable que debe ser protegido y ayudado por el profesional. En paralelo, y a pesar de reconocer en el discurso los potenciales beneficios que tiene, la JR es visualizada como una metodología que poco o nada tiene que ver con la reparación de la víctima (como anunció una entrevistada, AV se focaliza más en la relación con los juzgados que en apoyar a la víctima a encontrarse con el ofensor). Por su parte, la tensión entre necesidad y empoderamiento también parece estar presente entre los profesionales de JR, quienes tienen diferentes opiniones respecto a 
cómo, cuándo y de qué manera debe involucrarse una víctima en el proceso de JR.

De estas conclusiones se desprenden importantes tareas para la investigación y la política pública. En primer lugar, generar genuinos espacios de participación a víctimas de delitos implica abrirse a maneras más variadas de entender la victimización criminal (Dachy \& Bolívar, 2013). Es tan necesario estudiar y comprender la variabilidad de las necesidades de las víctimas de delitos como sensibilizar a los operadores sociales sobre (a) los beneficios y metodologías de la JR y (b) las competencias de las víctimas de delitos. En segundo lugar, se hace necesario un mayor desarrollo conceptual y científico de nociones como víctima vulnerable, evaluación de riesgo y resguardos en JR. Estas nociones son de suma importancia en el contexto de la implementación de la Directiva 2012/29/EU. Dichos desarrollos deben fomentar una mayor comprensión del fenómeno, sin buscar la estandarización de la respuesta estatal, y permitir, en vez de cerrar, la posibilidad de elegir.

\section{Referencias}

Aertsen, I. (2006). The intermediate position of restorative justice: The case of Belgium. En I. Aertsen, T. Daems \& L. Robert (Eds.), Institutionalizing restorative justice (pp. 68-92). Cullompton: Willan Publishing.

Aertsen, I., Bolivar, D., De Mesmaecker, V., \& Lauwers, N. (2011). Restorative justice and the active victim: Exploring empowerment. Temida, 14(1), 5-19.

Aertsen, I., Mackay, R., Pelikan, C., Willemsens, J., \& Wright, M. (2004). Rebuilding community connections. Mediation and restorative justice in Europe. Strasbourg: Council of Europe Publishing.

Aertsen, I., \& Peters, T. (1998). Mediation for reparation: The victim's perspective. European Journal of Crime, Criminal Law and Criminal Justice, 6(2), 106-124.

Angel, C. (2005). Crime victims meet their offenders: Testing the impact of restorative justice conferences on victims' post-traumatic stress symptoms (Tesis doctoral). Recuperada de Electronic Dissertations, Univer- sity of Pennsylvania (Paper AAI3165634). http:// repository.upenn.edu/dissertations/AAI3165634

Barton, C. (2000). Empowerment and retribution in criminal justice. En H. Strang \& J. Braithwaite (Eds.), Restorative justice: Philosophy to practice (pp. 55-76). Aldershot: Ashgate/Dartmouth.

Beven, J., Hall, G., Froyland, I., Steels, B., \& Goulding, D. (2005). Restoration or renovation? Evaluating restorative justice outcomes. Psychiatry, Psychology and Law, 12(1), 194-206.

Bolívar, D. (2010). Conceptualizing victim's 'restoration' in restorative justice. International Review of Victimology, 17(3), 237-265.

Bolívar, D. (2012a). Community of care from a victim perspective: A qualitative study. Contemporary Justice Review, 15(1), 17-37.

Bolívar, D. (2012b). Victim-offender mediation and victim's restoration. A victimological study in the context of restorative justice (Tesis doctoral inédita). KU Leuven, Lovaina.

Bolivar, D. (2014). La mediación víctima-ofensor como alternativa al sistema penal: la perspectiva de las víctimas. Sistema Penal Ė Violência, 6(1), 13-30.

Bolívar, D., Pelikan, C., \& Lemonne, A. (2015). Victims and restorative justice: Towards a comparison. En I. Aertsen, I. Vanfraechem \& D. Bolivar (Eds.), Victims and restorative justice (pp. 172-200). London: Routledge.

Braithwaite, J. (2002). Restorative justice and responsive regulation. Oxford, UK: University Press.

Centre for Innovative Justice. (2014) Innovative justice responses to sexual offending. Pathways to better outcomes for victims, offenders and the community. Victoria, Australia: RMIT University. Recuperado de http://mams.rmit.edu.au/qt1g6twlv0q3.pdf

Charmaz, K. (2006). Constructing grounded theory. London: Sage.

Christie, N. (1977). Conflicts as property. British Journal of Criminology, 17(1), 1-15.

Dachy, A., \& Bolívar, D. (2013). Implementing a better response to victims' needs. (Informe de investigación JUST/2010/JPEN/1601). Bruselas: Institut National de Criminalistique et Criminologie. Recuperado de http://incc.fgov.be/implementing-abetter-response-to-victims-needs 
Daly, K. (2000). Revising the relationship between retributive and restorative justice. En H. Strang \& J. Braithwaite (Eds.), Restorative justice, philosophy and practice (pp. 33-54). Aldershot: Ashgate.

De Mesmaecker, V. (2011). Perception of justice and fairness in criminal proceedings and restorative encounters: Extending theories of procedural justice (Tesis doctoral), KU Leuven, Lovaina.

Dignan, J. (2005). Understanding victims and restorative justice. Maindenhead: Open University Press.

Ehret, B., Dhondt, D., Fellegi, B., \& Szegö, D. (2013). Developing peacemaking circles in a European context (Informe final de investigación). Tübingen: Eberhard Karls University. Recuperado de http:// euforumrj.org/assets/upload/PMC_EU_2_Research_Report_Final_Version_RevVer-HJK.pdf

European Forum for Victim Services. (2003). Statement on the position of the victim within the process of mediation. Londres: Autor (hoy, Victim Support Europe).

Flaten, C. (1996). Victim offender mediation: Application with serious offences committed by juveniles. En B. Galaway \& J. Hudson (Eds.), Restorative justice: International perspectives (pp. 387-402). Monsey, NY: Criminal Justice Press.

Gustafson, D. (2005). Exploring treatment and trauma recovery implications of facilitating victim offender encounters in crimes of severe violence: Lessons from the Canadian experience. En E. Elliott \& R. M. Gordon (Eds.), New directions in restorative justice: Issues, practice, evaluation (pp. 193-227). Cullompton, UK: Willan Publishing.

Koss, M. (2014). The RESTORE program of restorative justice for sex crimes: Vision, process and outcomes. Journal of Interpersonal Violence, 29(9), 1623-1660.

Larson, J., \& Zehr, H. (2007). The ideas of engagement and empowerment. En G. Johnstone \& D. W. Van Ness (Eds.), Handbook of restorative justice (pp. 4158). Devon, UK: Willan Publishing.

Latimer, J., Dowden, C., \& Muise, D. (2005). The effectiveness of restorative justice practices: A metaanalysis. The Prison Journal, 85(2), 127-144.

Lauwaert, K. (2015). Victims and restorative justice in criminal justice policy at the European level. En I. Aertsen, I. Vanfraechem \& D. Bolívar (Eds.),
Victims and restorative justice (pp. 239-272). London: Routledge.

McCold, P. (2004). What is the role of community in restorative justice theory and practice? En $\mathrm{H}$. Zehr \& B. Toews (Eds.), Critical issues in restorative justice (pp. 155-172). Monsey, New York/ Cullomptom, Devon, UK: Criminal Justice Press/ Willan Publishing.

McCold, P., \& Wachtel, B. (2002). Restorative justice theory validation. En E. Weitekamp \& H. J. Kerner (Eds.), Restorative justice theoretical foundations (pp. 110-142). Cullompton, Devon: Willan Publishing.

Miller, S. (2011). After the crime: The power of restorative justice. New York/London: New York University Press.

Miller, S., \& Hefner, K. (2015). Procedural justice for victims and offenders? Exploring restorative justice processes in Australia and the US. Justice Quarterly, 32(1), 142-167.

Morris, A., Maxwell, G., Ë Robertson, J. (1993). Giving victims a voice: A New Zealand experiment. The Howard Journal, 32(4), 304-321.

Organización de las Naciones Unidas. (2006). Manual sobre programas de justicia restaurativa. Recuperado de http://www.unodc.org/documents/justice-andprison-reform/Manual_sobre_programas_de_justicia_restaurativa.pdf. 05.03.15

Pranis K. (2001). Restorative justice, social justice and the empowerment of marginalized populations. En G. Bazemore \& M. Schiff (Eds.), Restorative community justice: Repairing the harm and transforming communities (pp. 127-149). Cincinnati: Anderson Publishing.

Rappaport, J. (1981). In praise of paradox: A social policy of empowerment over prevention. American Journal of Community Psychology, 9(1), 1-25.

Roberts, T. (1995). Evaluation of the VOM project (Langely, BC: informe final no publicado). Victoria BC, CAN: Focus Consultant.

Rugge, T., \& Cormier, R. (junio, 2003). Restorative justice in cases of serious crimes: An evaluation. $6^{\text {th }}$ International Conference on Restorative Justice "Best Practices in Restorative Justice" held in Vancouver, British Columbia, Canada. http://www.sfu.ca/cfrj/ fulltext/rugge.pdf 
VÍCTIMAS EN JUSTICIA RESTAURATIVA: ¿SUJETOS ACTIVOS O EN NECESIDAD? UN ESTUDIO EUROPEO DESDE LA PERSPECTIVA DE OPERADORES SOCIALES

Shapland, J., Atkinson, A., Atkinson, H., Chapman, B., Dignan, J., Howes, M., ... Sorsby, A. (2007). Restorative justice: The views of victims and offenders. The third report from the evaluation of the three schemes. South Yorkshire, Reino Unido: Center for Criminological Research, University of Sheffield. Recuperado de http://www.justice.gov.uk/docs/ Restorative-Justice.pdf

Shapland, J., Robinson, G., \& Sorsby, A. (2011). Restorative justice in practice. Evaluating what works for victims and offenders. London: Routledge.

Sherman, L., \& Strang, H. (2007). Restorative justice: The evidence. Londres: The Smith Institute. Recuperado de http://www.smith-institute.org. $\mathrm{uk} /$ publications.html\&search= restorative $\% 20$ justice\&category_id $=11$

Sherman, L., Strang, H., Mayo-Wilson, E., Woods, D., $\&$ Ariel, B. (2014). Are restorative justice conferences effective in reducing repeat offending? Findings from a Campbell Systematic Review. Journal of Quantitative Criminology, 31(1), 1-24.

Strang, H. (2002). Repair or revenge: Victims and restorative justice. Oxford: Clarendon Press.

Strang, H. (2004). Is restorative justice imposing its agenda on victims? En H. Zehr \& B. Toews (Eds.), Critical issues in restorative justice (pp. 95-106). Monsey, NY: Criminal Justice Press.

Strang, H. (mayo, 2012). Restorative justice and the life course. Trabajo presentado en el seminario Restorative Justice in New Arenas en el International Institute for the Sociology of Law, Oñati, Spain.

Umbreit, M. (1994). Victim meets offender. The impact of restorative justice and mediation. New York: Willow Tree Press.

Umbreit, M., Coates, R., \& Vos, B. (2004). Victimoffender mediation: Three decades of practice and research. Conflict Resolution Quartely, 22(12), 279-303.

Umbreit, M. S., Coates, R. B., Vos, B., \& Brown, K. (2003). Facing violence: The path of restorative justice and dialogue. Monsey, NY: Criminal Justice Press. Vanfraechem, I., Bolívar, D., \& Aertsen, I. (Eds.). (2015). Victims and restorative justice. London: Routledge.
Van Camp, T., \& Wemmers, J. -A. (2013). Victim satisfaction with restorative justice: More than simply procedural justice. International Review of Victimology, 19(2) 117-143.

Walgrave, L. (2008). Restorative justice, self-interest and responsible citizenship. Cullompton: Willan Publishing.

Wemmers, J. -A., \& Canuto, M. (2002). Victims' experiences with, expectations and perceptions of restorative justice: A critical review of the literature (Informe). Montréal: Department of Justice Canada. Recuperado de http://www.justice.gc.ca/eng/rp-pr/cj-jp/ victim/rr01_9/rr01_9.pdf

Wemmers, J., \& Van Camp, T. (2011). The offer of restorative justice to victims of violent crimes: Should it be protective or proactive? Montréal: CiCC, Université de Montréal. Recuperado de https://depot.erudit. org/bitstream/003511dd/1/Rapport\%20de\%20recherche\%20n4\%20Wemmers\%20Final.pdf

Zebel, S. (2012). Un estudio cuasi experimental sobre los efectos del programa holandés 'dialogo victima-ofensor'. En I. Weijers (ed) Diálogos victimaofensor. A la sombra del proceso penal.

Zehr, H. (2002). The little book of restorative justice. Intercourse, USA: Good Books.

Zehr, H. (2005). Changing lenses: A new focus for crime and justice. Scottsdale: Herald Press, PA.

Zinsstag, E., \& Keenan, M. (2015). Developing integrated responses to sexual violence: An interdisciplinary research project on the potential of restorative justice (Informe Daphne Project JUST/2011/DAP/ AG/3350). Leuven, UK: Leuven Institute of Criminology.

Zinsstag, E., \& Vanfraechem, I. (Eds.). (2012), Conferencing and restorative justice. International practices and perspectives. Oxford: Oxford University Press.

Zimmerman, M. (2000). Empowerment theory. Psychological, organizational and community levels of analysis. En J. Rappaport \& E. Seidman (Eds.), Handbook of community psychology (pp. 43-63). New York: Kluwer Academic. 
